\title{
¿Hay una individualidad poética o artística?
}

\section{A propósito de Alfonsina Storni}

Cuando, muy temprano, en la mañana del 26 de octubre del año 1938, abri, como de costumbre, el radiorreceptor para enterarme de los últimos acontecimientos del mundo y escoger el tema de la columna de actualidad internacional que escribía diariamente, oí, conmovido, anunciar el suicidio de Alfonsina Storni. Cuanto siguió en la radiotransmisión: gestiones y actitudes de las grandes figuras de la política mundial, hechos trascendentales que podían traer: el sosiego o la inquietud a toda la especie humana, jalones brillantes del arte o de la ciencia, perdieron su valor para mí, obstinado en imaginar, como para sacarle una inútil contestación, el cuerpo exánime de una mujer con ojos de ingenua dulzura y de "amplio renombre", llevado y traído por las aguas en el litoral de su país, allá en la América del Sur. Y contra todas las consideraciones para elegir otro tema, ese dia dediqué mi comentario a la desaparición de la insigne argentina que había cantado con tan profunda sensibilidad, "El dulce daño" e "Irremediablemente".

Ante seres así, resulta inevitable preguntarse si existe, con separación de la idiosincrasia común a los demás seres humanos, una individualidad poética o artística. La respuesta se encarga de ofrecérnosla, aunque parezca contradictorio, la propia vida con sus rutinas y trivialidades cotidianas. No; en el hombre corriente la vida o las cosas sólo lcgran una interpretación vegetativa o cuando más, literal. El poeta o el artista, en cambio, parecen sentir o ver de otra forma, como si descubriesen en cuanto los rodea una escala de 
maravillas, o sus sentidos se prolongasen en todo lo que es o puedo ser. Para su prodigiosa receptividad, por ejemplo, no hay un solotipo de tarde hermosa. Ni una misma tarde deja de contar con una serie infinita de variedades o gradaciones. Sería inagotable lo que yodrían percibir en un solo rayo de sol, o en una misma porción de cielo azul, y maestros en el secreto de cada sonido o de cada ráfaga de perfume, por minúsculos o fugitivos que sean, no hay burbuja de emoción, ni gajo de alegria, ni hilo de interés que no capten o no sepan apreciar. Podría decirse sin hipérbole que son como los verdaderos evaluadores de la vida o de la naturaleza, o como si Dios, el creador por antonomasia, hubiera trabajado exclusivamente para ellos o hallara, por lo menos, en su sensibilidad excepcional la comprensión que un creador quiere y necesita hallar en su público.

En cuanto a esa embriagadora sublimación de la sensibilidad que es el amor, si aman, cabria asegurar que sus corazones se han hecho la síntesis o el centro del mundo. Alguien ha dicho -y no interesa para el caso precisar quién ni discutir el valor de su juicio- que la risa es el don que distingue al ser humano, de los otros seres del cosmos. Parece más justo pensar que es el amor. Pero el amor. No la "cuota" que se paga como podría pagarse un tributo o impuesto fiscal en la taquilla correspondiente, y que empujando y estremeciendo todas las modalidades del ser, desde las organizaciones más rudimentarias de la vida, hasta los tipos más avanzados de nuestro inmediato antecesor, el irracional, hace que cl "rey de la creación" resulte vencido por ironía, a causa precisamente de su más alto timbre de superioridad, esa "espada de dos filos" que es el pensamiento. No. Me refiero al amor de los grandes sensitivos o soñadores. William Blale, sensitivo formidable, "diabólico y santo" al mismo tiempo, ha afirmado quizás con harta razón: "Todas las formas son perfectas en el espíritu del poeta". Poeta con significación substancial, esto es, no solamente el que escribe poesía, también cuantos la sienten o pueden. vivirla de algún modo. Unicamente con ese amor, fuerza, superación, milagro, infinitud, no sale mal parada la dignidad y la categoría de la raza humana.

Desde luego, los que no son muy optimistas respecto a las virtudes de la sensibilidad, probablemente miren con desdén a quienes sienten de manera extraordinaria. "Sensible", "la sensibilidad", di- 
cen muchos como si se tratara de tina carga. Olvidan que Dios es Dios porque, supremo sensible; repercuten en su ser los sentimientos $y$ los deseos de todos los hombres. $Y$ por lo que toca a esa infaltable secuéla de la sensibilidad, la imaginación ¿ no ha sido la imaginación pór excelencia, la autora del universo? Hasta en la sabiduría, los sabios que más nós cautivan o convencen, son los que se hallan más cerca de la poesía o del poeta. El propío Blake dijo escribiéndola con mayúscula: "El mundo de la Imaginación es el mundo de la Eternidad".

' Sobra decir que sensibilidad superior, no entraña necesariamente anormalidad o extravagancia. No veo cómo vivir entre la mugre garantice la posesión de genio o de talento. El tipo del artista o poetá que se pasa el día sudoroso, desastrado, ante la mesa de un café como un recurso íngenuó y vano para probar su condición de poeta o de artista, ha quedado, por fortuna, en el ayer. Por el contrario, una sensibilidad excepcional stipone la afición por la pulcritud en cualquier orden. Un hombre, psíquica o materialmente pulcro, es ser que no contradice la armonía universal. $Y$ los grandes sensitivos responden como nadie a la armonía de la creación. Frente a los teorizantes o los partidarios de lo malsano en arte, no se puede olvidar que la belleza, norte de soñadores y de artistas, es una ética sensibilizada y tolerante, pero rigurosa al fin y al cabo como todas las éticas. Quizás no estaría demás hacer la revisión del petimetre. Se lograría tal vez descubrir analizando un poco, que es el suyo un concepto tan alto del amor, hasta concebir que sólo se puede oficiar en su reino con la más flamante apostura. Si hay necesidad de la bohardilla o el camaranchón; muy bien. Me descubro ante los gloriosos raídos o desarrapados de todos los tiempos. Una semana sin pan, con la soledad por compañia y la miseria por horizonte sobrepasa en valor a cuanto pudo escribir Homero. Pero hay que volverse contra el alarde y la simulación, tan inaceptables e insufribles como la copia y la receta. Jamás he podido convencerme de que la rebeldía - que cuando es genuina tiene su pudor- estribe en hacerse desigual el lazo de la corbata, o en torcer la boca con sorna ante toda manifestación de ternura o sentimiento. ¿Es que puede contradecir el genio de un creador, la casa cómoda, empapada de luz, que parece girara sin descanso por las habitaciones, y la paz de un amor dulce $y$ bueno, y cuando el día empieza a declinar, irse 
por los caminos, no importa que sea en su propio automóvil o por sus mismos pies, mirando unos ojos que lo miran, y rodeados por uno de esos crepúsculos rojos que en vez de excitar, sumen en un gozo tan profundo, que es casi un suave temor de quebrar o interrumpir su maravilla, o envueltos en uno de esos crepúsculos de tan furibunda amarillez que semeja pulverizarse y volar infiltrándose en todo, menos en la parda silueta de los árboles, cargados como en cada oscurecer, de su melancólica ceniza? En el artista o el poeta hay un, solo límite: el de su dignidad de creador y de hombre.

Lo curioso, no obstante, es cuando se trata de la convivencia o el reajuste de la vida cotidiana, que por lo general no son los grandes sensitivos los menos avenibles o los más intransigentes. La mayor dificultad se halla en el "otro lado", entre los de individualidad corriente o común, empeñados en utilizar como vehículo inapelable de toda convivencia o asociación, el molde de la "rasante" mayoría. Es verdad que se ha caminado mucho en la eliminación de los abismos y dificultades que separan las distintas individualidades o sectores humanos. En el presente, no se discute que una gran sensibilidad pueda darse en el sector que podríamos considerar más antagónico a esa idea o condición, según el rígido criterio del pasado. Ni siquiera se habla ya de sectores. El término "burgués" pasó con las flotantes chalinas y las copiosas melenas. Es que aun sin darse bien cuenta, el hombre se reúne o se parece, al menos en el sentido social, cada vez más al hombre.

Desgraciadamente, eso no es bastante. Vivimos una de las épocas más contradictorias de la humanidad. De atenernos a ciertas señales, podríamos creer en un elevado indice de desarrollo espiritual. Pronto viene el convencimiento, sin embargo, de que son sólo testimonios de la lucha que sostienen el hombre, o algunos hombres, por no sucumbir entre la desorientación en que parece debatirse el destino de la familia humana. No pretendo hacer una negación radical. Acaso en ninguna época como en ésta, el hombre llegó a tener sentido del confort, de manera más ágil y deliciosa. $\mathrm{Ni}$ tal vez tuvo nunca mejor intención de darle un sitio en su vida a la naturaleza. Lo innegable es que pocas etapas en la historia de la humanidad más enconada contra cuanto signifique idea de exquisitez o perfección. $\mathrm{Y}$ de invocarse como justificación de tal proceder la utilidad de concluir con el convencionalismo, debemos recordar que en re- 
sumen la civilización, tomándola en carácter genérico o como sucesión de cambiantes civilizaciones, no es más que la conquista de una serie de afinamientos y convencionalismos: los afinamientos superantes y los convencionalismos imprescindibles. Es que para el hombre - hombre en el concepto cósmico o cardinal- hasta la misma biologia es una convención.

De la mayor o menor elevación de una época hablan, con elocuencia incontrovertible, las garantías que ofrece o no para conservarle a la mujer esa categoría trascendental que le adjudicó el hombre civilizado. El ajuste de la mujer como valor sentimiental en la vida y la actividad del hombre es, sin disputa, una de las características fundamentales de la civilización. Entre esa noción o valoración de lo femenino y la desaliñada y ruda compañera del troglodita, del troglodita para quien la mujer no rebasa de utensilio doméstico, similar al hacha de sílex, la espina de pescado o la piel de las fieras, hay todo un mundo halagador de cambios y sublimaciones. Hoy, tan pronto una muchacha sale a la vida, encuentra como una confabulación para embastecerla. Si asediada por esa plural coacción, concluye por ceder, en una especie de retorno a la más rutinaria expresión del instinto de su abuela troglodita ¿podría asombrar que el hombre, el varón, a la vez su principal defraudador y el culpable, pero que aun en el espécimen más burdo aspira a encontrar en la mujer un valor extraordinario; sea el primero en sentirse defraudado, y mordido por malestar que quizá no sepa definir o no advierta de modo consciente, acabe, falto del estímulo tradicional para superarse, por empequeñecerse, y caiga la humanidad en un marasmo doloroso?

Alfonsina Storni nació predestinada para sentir. Fué de esos seres a los que cabe bien la definición de "sensibilidad que piensa y anda". Todo debió concertarse para que lo fuera. Ni siquiera el nacer en las tierras templadas de Europa le restó fuerza a esta predestinación, porque nacida en esas regiones alpinas de montañas nevadas y aire de asombrosa limpidez, la circundó esa exaltación de la nieve y el cielo azul, no por callado, con menos frenesí que la vocinglera exaltación de las tierras del trópico, de crujiente sol y rechinante verde. Luego fué a crecer y formarse en la Argentina. Los pueblos de Hispanoamérica sugieren algo de vegetal. En la sugestión provocada por la milagrosa supervivencia de la modalidad de sus orígenes. Frutos, en su mayoría, de la fusión de las selvas en su más 
palpitante espontaneidad y del hábito urbano del español o el europeo, subsiste, todavía en el mismo complicado y vertiginoso torbellino de sus grandes poblaciones, esa impresión de bosque o de campo. Podríamos estimarla como supervivencia providencial. Porque como dije hace tiempo, el hispanoamericano necesita de la tutela permanente del árbol o llevar prendido un gajito de bosque o de campo en el corazón, para que no se le seque. Quizás de todas las tierras de la América hispana, sea la Argentina, a pesar del alto índice que alcanza allí la vida moderna con sus múltiples actividades e inquietudes, una en las que más perdura esa fresca sugestión. Por lo que concierne al substrato sentimental del pueblo argentino basta para medirlo, con acordarse -no importa el origen que cierta, crítica le atribuya - de esa epopeya cadenciosa y comprimida que es el tango.

Se ha dicho que Alfonsina. Storni, profesora hasta el fin de su vida, se hizo muy joven maestra rural. Es una insinuante coincidencia. No escasean en la literatura hispanoamericana las poetisas relacionadas con la enseñanza. Sor Juana Inés de la Cruz, en el México de los virreyes, y Sor Leonor de Ovando, en el Santo Domingo colonial, riman más de una vez con acento y alcance pedagógicos. Salomé Ureña de Henríquez, èn el Santo Domingo republicano, es tan poetisa ilustre como educadora sobresaliente. Maestra fué asimismo su compatriota Altagracia Zoraida Saviñón, sorprendente promesa de la lírica americanra que malogró la desventura. En Chile, Gabriela Mistral, de pobre maestrita autodidacta y provinciana, se convierte muy pronto' en educadora continental. Luisa Luisi, la eminente poetisa uruguaya, vivió de cerca los problemas de la educación. $\therefore$ Es que la sensibilidad excepcional de estas mujeres las hace experimentar, como una bella forma de creación, el irresistible deseo de elevar el pensamiento y el alma de sus semejantes? Pero no son solamente las mujeres, las poetisas, sino los poetas, los hombres también: Andrés Bello, poeta, fué además inolvidable preceptor; José Martí, como en la vida y con su vida, enseñó desde una cátedra; "Almafuerte" trabajó en una escuelita rusticana; Luis Gabriel Urbina y Salvador Díaz Mirón dieron clases en el exilio; Leopoldo Lugones tuvo todo el perfil de un maestro y Eugenio María de Hostos, poeta dentro del sentido estricto de tal denominación, como lo prueban "La peregrinación de Bayoán" y la ternura des- 
bordante de su "Diario íntimo", contó tal vez como el mayor fundamento de su actividad de sabio y educador, su vigor de poeta.

Por otra parte, si Alfonsina Storni cultivó el teatro con éxito desde el punto de vista literario en si, el hecho constituye otra afirmación de su gran sensibilidad. Diálogo es el teatro. Y en diálogo, en perenne diálogo se resuelve el espíritu de los grandes sensitivos. Diálogo entre lo que se posee y lo que no se tiene, entre lo que se quiere hacer: $y$ lo que se opone a que lo hagan la parte de razón común que se les filtra, a despecho de sí mismos, entre la visión de su realidad y la realidad que le enfrentan los otros como la versión de los hechos y las cosas, indiscutible y única.

La dolorida poetisa de "Ocre" ha declarado en los versos finales de aquella poesía en que con trece años de antelación trazó el epitafio de su tumba:

Como es mujer grabó en su sepultura

Una mentira aún: la de su hartura.

Confesión concluyente. Pero mentira no sólo de su hartura, igualmente la de su ironía para cuanto se refiere al sentimiento: $Y$ aun la de su ironía en general. Los grandes sensitivos ríen o ironizan para esconder su ternura o su sensibilidad como un don vergonzoso ante las ingratas correspondencias de la vida. Eso fué Alfonsina Storni, un alma resentida e insaciada. He escrito solamente: un alma. No debe. confundirse el objeto de esta limitación, ni desprendérsele consecuencias que no tiene. Desde luego, una gran sensitiva que sufre el torcedor de sus grandes sentimientos y el fracaso de sus más grandes ilusiones, de no retorcerse en un sobrehumano misticismo, lo más fácil es que concluya por sentir el deslumbramiento de la sensación. Recordemos que con la sensación principia a dominarnos la belleza. Alucinada por la sensación, Alfonsina Storni la capta, la estimula, la aguza, la aprovecha, la agota hasta términos insospechados, pero sin virus ni avideces enfermizas. Su sensualidad es la de la naturaleza: ardiente en el sol y refrigerante en el agua. Lo incontestable es que pocos seres humanos han dispuesto para la sensación, de aparato más agudo. Pero la poetisa, en cuyos versos es casi motivo común "andar descalza por los viejos corredores y la grama húmeda de los jardines", y que de buena gana se 
iría "por los campos bajo la lluvia fina", libr̨e la cabellera como un ala, se queja de verse "rodeada por apáticas almillas":

que no saben ni un ápice siquiera

de esta fiebre azulada que nutre mi quimera.

O se lamenta con entrañable tristeza:

¡Cárcel de los sentidos que las cosas me han dado!

Ah, yo del universo no me puedo escapar...

Por lo demás, en un creador, no empecen los propósitos de "evasión" o de ocultamiento, el espiritu, la "esencia" no engaña. Su huella queda en lo creado de manera inequívoca. Las mismas inquietudes, los propios problemas, los motivos básicos que impulsaron los libros de sus primeros periodos, persisten en "Ocre" y la producción subsiguiente, no obstante las innovaciones formales, la expresión más cerebral en consonancia con una madurez; difícil en una sensitiva de que llegara al corazón, pero que al tocarle el pensamiento, lo "obligó" quizás en nombre de una "sensatez" preceptuada por los códigos de la insensibilidad y la rutina -aun para las "cosas ilegislables del sentimiento"- a frenar el vuelo lírico, aunque le dejase abiertas, disfrazadamente o no, las puertas compensatorias de lo sensual. Por cierto que en estos últimos períodos, su verso adquiere en gran parte nitidez y precisión pasmosas, y el logro de la originalidad se remonta a lo superlativo.

Puede que no se refleje con más exactitud la tragedia intima de la poetisa como en dos composiciones de ambiente familiar. En ambas no hay protestas ni desolación a gritos. Es una amargura estática en que hasta las lágrimas si corren es gota a gota. $\mathrm{E} 1$ dolor mudo del contraste, de la comparación que le basta para imponerse, con su atroz insolubilidad y su mudez desgarradora. En una ("Han venido") la madre y las hermanas llegan por fin a verla ("hace tiempo que yo estaba sola - Con mis versos, mi orgullo; en suma nada"). Una de las hermanas, la mayor, "está crecida", "es rubiecita" y "por sus ojos pasa el primer sueño". Y la poetisa que la ha visto y ha pensado, le dice repentinamente, como en una fuga, a la menor: "la vida es dulce. Todo mal acaba..." Pero la madre que no se deja engañar por aquella declaración de optimismo, como no 
se dejan nunca engañar las madres, "sonríe" y "poniéndole las manos en los hombros", la mira "muy fijo" y de las pupilas de la lírica salta el llanto. En la otra composición ("Mi hermana") la hermana "con quince abriles en los ojos limpios y claros" duerme en su alcoba, con las manos virginales sobre el pecho. Ya la poetisa, que es "el verano, y ya lo sabe todo", vigila cuidadosamente su sueño y le suplica "a los que han de amarla un día" o hablarle de amor: "Sed buenos", "su alma como cera se labra - pero como a la cera el roce la destruye". "Cuidad vuestra palabra y la intención"; "velad si os es posible por su nevado huerto". "Yo lo sé todo, es cierto. Pero ella es como el cielo : ella no sabe nada" .. Saber ... Alfonsina Storni vió, soñó, pidió, creyó y supo. Sí, supo. Qué dulce y valiosa aparece entonces para los que han sabido, la divina ignorancia de los que conservan incólume el tesoro de sus sueños...

Pero si la Alfonsina Storni "esencial", se muestra a través de toda su obra, lo hace especialmente en su primera etapa (a cuya costa parece que ironizó un tanto en el autoprólogo a la Antología de sus versos editada en la Argentina hace algunos años) cuando exenta de prejuicios, responde con su cabal intensidad a la solicitud del sentimiento. Como la Antígona de Sófocles nació para el amor. Es una "amorosa" en la noble acepción del vocablo. Grandes amorosos llenan y engrandecen la historia del arte y del mundo. La poetisa no escribió falsamente refiriéndose al amor: “¿Dónde estará lo que persigo ciega?". Quién, amando, ha podido cantar: "Polvo de oro en tus manos fué mi melancolia", no es extraño que ruegue:

Sálvame amor y con tus manos puras

Trueca este fuego en límpidas dulzuras

$Y$ haz de mis leños una rama verde.

Es que si la "despreocupada", la "rebelde" insiste en hacer alarde de su "despreocupación" o de su "rebeldia", o le niega a los hombres, como en "Tú me quieres blanca" (escrita nada menos que a los veinte años) derecho a recusarla, es porque la preocupa que puedan discutirle la capacidad plena para lo que es su congénita vocación: el amor absoluto.

Parece improbable que en nuestra lengua el amor haya tenido creyente más elevada e intérprete más eficaz que la Alfonsina Storni de "Canción de la novia". y "La casa": 
¡Moría casi! Me llevaste tierno,

Por largas escaleras silenciosas.

$\mathrm{Y}$ ni tuve conciencia de las cosas:

Era un cuerpo de luna sin gobierno.

Y mi alma también rodó en el río,

Se hut1dió con él en perfumadas frondas,

Siguiéndolo hasta el mar cayó en sus ondas

$\mathrm{Y}$ suyo fué el divino poderío.

Subió hasta las ciudades de otro mundo;

Dormían todos, todo estaba blanco:

Luego vió cada mundo como un banco

De arena muerta en el azul profundo.

$Y$ desde aquel azul que todo abisma

Miró en la Tierra esta ventana abierta :

¿Quién era esa criatura medio muerta?

$\mathrm{Y}$ se bajó a mirar. $\mathrm{Y}$ era yo misma.

En una mujer, en una poetisa, en una sensitiva que sintió y aun sufrió de ese modo, porque en su "vida velaba un grave amor inmenso que no podía saciar", y que si llegó a sentir que se le iba de los dedos "la caricia sin causa", conocía muy bien que ella misma era "una caricia" que vagaba sin destino y sin objeto, no puede sorprender ni la frecuente cita de la primavera, signo de la oportunidad, según la tradición, de saciar total y fácilmente la ilusión amorosa, ni su obsesión o devoción por la muerte y el mar. La muerte es valor tan absoluto que se impone por sí mismo. El mar es la ilusión de lo infinito o de su adaptación humana: la libertad. El hombre quiere y busca la libertad para no tener límites. He pensado en más de una ocasión, si Alfonsina Storni, decepcionada de la tierra firme, donde ni la noción de su propio ser correspondió quizás al modelo que la inmensidad de su ambición le prefigurara, aspiraría a conseguir en el mar la compensación o el desquite de un mundo maravilloso de tritones y nereidas. De ser así, el mar como el amor tampoco supo corresponderle o reciprocarle su preferencia, pues confirmando la hipótesis que me hice al conocer la noticia de su nituerte, las olas mecian su cuerpo en una equidistante amarga y simbólica entre el océano y las arenas de la playa.

Hay una soledad "exterior" que puede afectarnos fuera o en medio de la gente. Es desagradable y penosa, pero no absoluta. La 
absoluta tiene nombre más cruel : incomprension. Sentirse incomprendido equivale a llevar toda el alma en perpetua llaga, condenado al aislamiento eterno como los abrumados por una condenación bíblica. En la misma poesía puede ocurrirle a la poetisa por más de una oportunidad que instigada por sus sueños, pusiera toda su fe en un poema para obtener la comprensión de alguien, y éste, tras de leerlo diez veces, le contestara como el crítico "famoso" de que habló José Asunción Silva: "No entiendo". Incomprensión en la vida e incomprensión tal vez en el arte, que es una segunda manera de vivir, no es raro que ofusquen y lleven al camino que eligió la rebelde poetisa de "Mundo de los siete pozos".

Aceptada la existencia de una individualidad poética o artística ¿cuál serían la colocación, como la interpretación adecuaclas que podría dársele en la comunidad humana? Una mañana de invierno en Nueva York, no clara y hermosa como hay muchas, sino helada y gris, tropecé con una de las obras de la honda cantadora de "Languidez" en una librería. Minutos después encerrado en mi habitación leía ese libro, y no puedo explicar qué produjo en mi cspiritu el contraste de la atmósfera dulcemente cálida del cuarto y de la nieve que miraba caer por la ventana, que me prometí escribir un estudio como éste. Pasaron los años y no cumplí mi promesa. Pero ahora experimento la satisfacción de estar terminando de hacerlo. Naturalmente, no confío ni mucho ni poco en lo que pueda ser o dar, pero si a pesar de su mezquindad, contribuyere siquiera un tanto para que se conceda a los grandes sensitivos algo como una carta de ciudadanía tocante a un país o medio ideal (que bien pudiera hallarse por encima de las fallas y las incomprensiones humanas) y que les sirva de salvoconducto para moverse libremente por el mundo en goce y procuración de sus sueños, o al menos que a su deseo de azul, se transija en que tengan un poco de azul entre la rutinaria sensibilidad de los demás miembros del género humano, creería regocijado que había conseguido mucho. ¿No es cierto, Alfonsina Storni?

Angel Rafael Lamarche 
